\title{
Unusual electrocardiographic changes in Ebstein's anomaly
}

\author{
F. Follath ${ }^{1}$ and K. A. Hallidie-Smith \\ From the Department of Medicine (Clinical Cardiology), \\ Royal Postgraduate Medical School, London W.I2
}

The electrocardiograms of $I 7$ patients with Ebstein's anomaly of the tricuspid valve were analysed. Right bundle-branch block or Wolff-Parkinson-White syndrome (WPW) was found in the majority of patients, but there were several unusual electrocardiographic changes, including

+ ventricular pre-excitation with normal PR interval (2 patients) and incomplete right bundlebranch block with broad $Q$ waves suggesting inferior wall infarction (I patient). The mechanisms and clinical importance of these findings are discussed.

Electrocardiographic changes have an important diagnostic contribution in Ebstein's anomaly of the tricuspid valve. Right bundle-

branch block is found in 70-80 per cent of patients (Vacca, Bussmann, and Mudd, 1958; Schiebler et al., 1959b; Genton and Blount, 1967), usually with bizarre splintering of the QRS complex and low voltage in right praecordial leads. The intraventricular conduction defect is frequently associated with signs of

\$ right atrial overload and a prolonged PR interval. Ebstein's anomaly is also the most common cardiac malformation in children with the Wolff-Parkinson-White syndrome (Schiebler et al., 1959a, b).

Among our patients with Ebstein's anomaly we have recently observed some unusual electrocardiographic findings which initially suggested a different diagnosis and/or the

- presence of additional complications. The electrocardiograms of these patients are presented in this paper.

\section{- Patients and method}

The electrocardiograms of 17 patients ( 6 children aged 3-I4 years and II adults aged 16-57 years)

$=$ with Ebstein's anomaly were analysed. The diagnosis was confirmed by angiocardiography and/or necropsy in all. There were 3 deaths; the other I4 patients are alive and well.

\section{Results}

The electrocardiographic findings in the 17 $+x^{\prime}$ patients are summarized in the Table.

Received 19 July 1971.

1 Present address: Division of Cardiac Surgery, University Hospital, Basle, Switzerland.
There were 3 types of unusual electrocardiographic abnormalities among these patients: these will be illustrated by case reports.

(A) Delta waves with normal PR interval and left axis deviation

Case I An acyanotic woman, aged 57 years, complained of frequent attacks of paroxysmal tachycardia for to years. Ebstein's anomaly was diagnosed clinically and confirmed by angiocardiography at the age of 55 years. During an attack of supraventricular paroxysmal tachycardia aberrant intraventricular conduction of right bundle-branch block type was present (Fig. I). Subsequent electrocardiograms showed sinus

TABLE Electrocardiographic findings in 17 patients with Ebstein's anomaly

\begin{tabular}{|c|c|}
\hline $\begin{array}{l}\text { Right bundle-branch block }(R B B B) \\
\text { RBBB, low voltage in VI, and right } \\
\text { axis deviation } \\
\text { RBBB, tall } \mathrm{R}^{\prime} \text { in } \mathrm{VI} \text {, and left axis } \\
\text { deviation } \\
\text { I RBBB with rSr's' in } \mathrm{VI} \text { and } \\
\text { abnormal Q waves } \\
\text { I RBBB }\end{array}$ & $\begin{array}{l}4 \text { patients } \\
2 \text { patients }\end{array}$ \\
\hline Total & Io patients \\
\hline (Right atrial overload & 6 patients) \\
\hline $\begin{array}{l}\text { Ventricular pre-excitation } \\
\text { Type B Wolff-Parkinson-White } \\
\text { (WPW) } \\
\text { WPW with left bundle-branch block } \\
\text { Delta waves with normal PR interval }\end{array}$ & $\begin{array}{l}4 \text { patients } \\
\text { I patient } \\
2 \text { patients }\end{array}$ \\
\hline Total & 7 patients \\
\hline
\end{tabular}



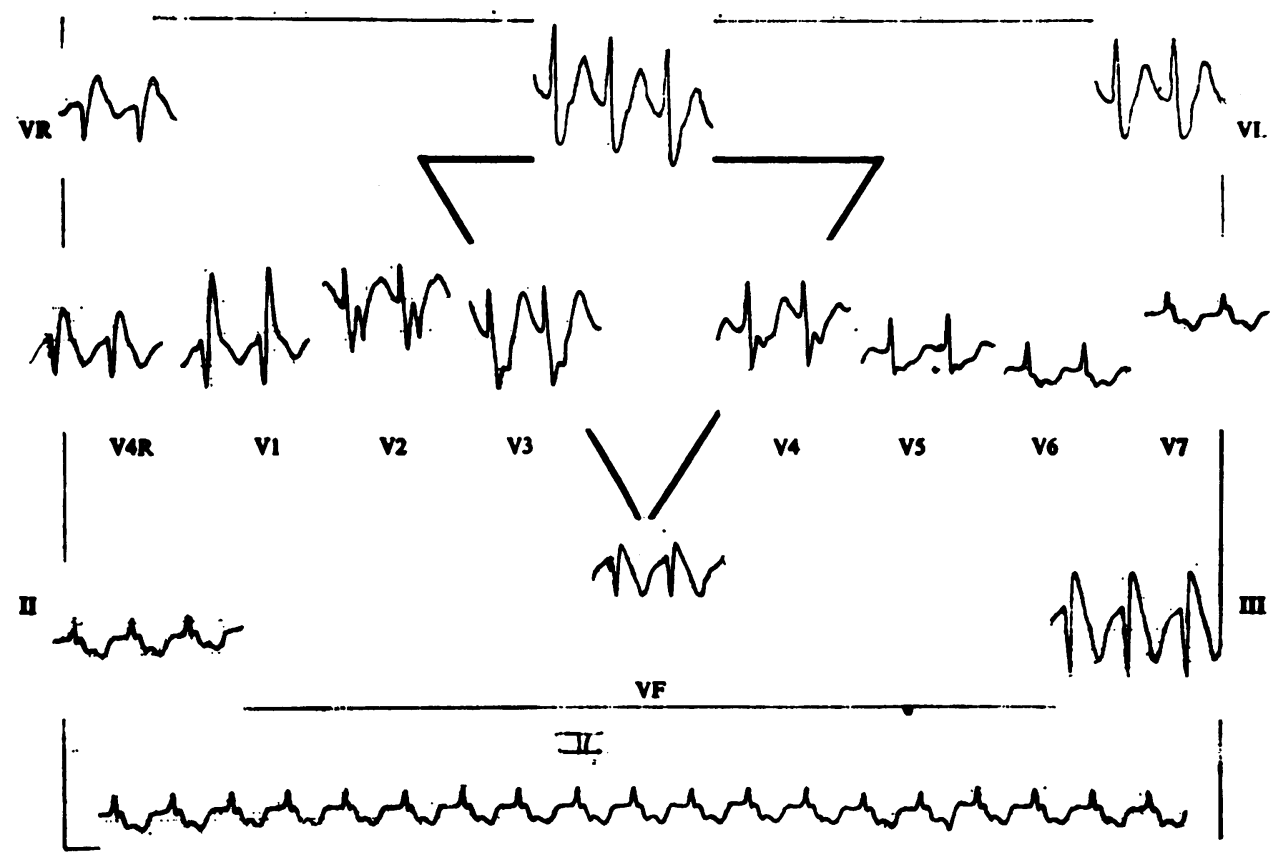

FIG. I Case I. Supraventricular tachycardia with right bundle-branch block. No visible delta waves.

FIG. 2 Case I. Electrocardiogram showing WPW syndrome with normal PR interval $(0 \cdot 16 \mathrm{sec})$ in the same patient after cessation of paroxysmal tachycardia.

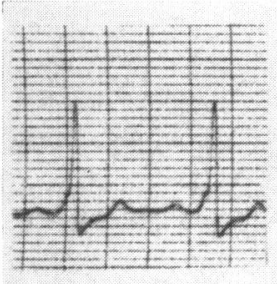

I

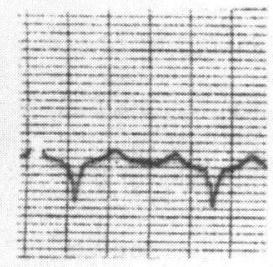

II

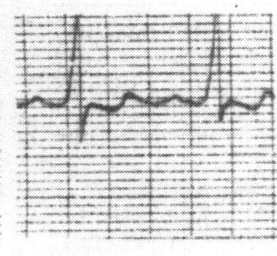

$\mathrm{V}_{2}$

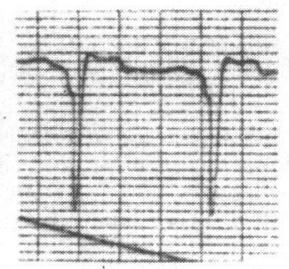

III

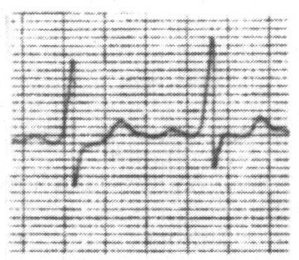

$\mathrm{V}_{3}$

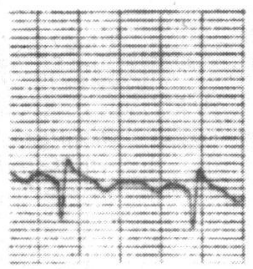

aVR

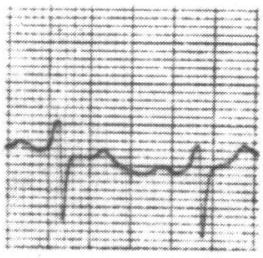

$\mathrm{V}_{4}$

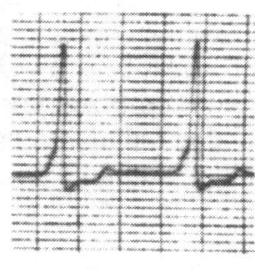

aVL $\underline{\underline{w}}$

\)

.

당

흥

จำ

in

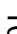

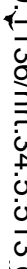

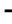

c

N

D

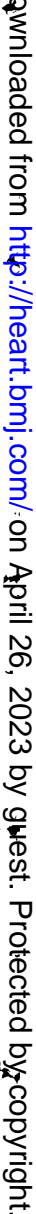


rhythm, a PR interval of 0.14-0.16 sec, QRS duration of $0.1 \mathrm{sec}$, and delta waves in leads $I$, aVL, and $\mathrm{V}_{5}-\mathrm{V}_{7}$. There were prominent negative delta waves in leads II, III, and aVF (Fig. 2). In - no tracing was a short PR interval found.

Case 2 A 5-year-old cyanotic girl had attacks of paroxysmal tachycardia. A short scratchy systolic murmur at the left sternal edge, a widely split second heart sound, and right atrial enlargement on the chest $x$-ray suggested Ebstein's anomaly, which was proven by angiocardiography. The - electrocardiograms showed sinus rhythm, a PR interval of $0.18 \mathrm{sec}$, a mean QRS axis of $-45^{\circ}$, and delta waves in leads I and V4-V6. The QRS duration was $0.08 \mathrm{sec}$ (Fig. 3).

(B) Wolff - Parkinson - White syndrome with left bundle-branch block

Case 3 In a 29-year-old woman a systolic murmur was detected in early childhood. She was never cyanosed and remained asymptomatic until the age of 17 years, when she started to have attacks of paroxysmal tachycardia accompanied by breathlessness and chest pain. In 1964 the diagnosis of hypertrophic obstructive cardiomyopathy was made, which seemed to be supported by the angiographic appearance of septal hypertrophy. The patient was treated with propranolol $80 \mathrm{mg}$ daily without notable effect. In 1970 she was referred to Hammersmith Hospital for further investigation. No signs of left ventricular dysfunction could be found and the diagnosis of Ebstein's anomaly was suspected on the basis of a scratchy systolic murmur on the left sternal edge, split first and second sounds, and the Wolff-ParkinsonWhite syndrome (Type B). The diagnosis was subsequently confirmed by intracardiac electrography and angiocardiography. The electrocardiogram showed ventricular pre-excitation with a PR interval of 0.10 sec and definite delta waves in leads I, II, aVL, and V4-V7. The QRS complex

FIG. 3 Case 2. WPW syndrome in a child of 5 years with a PR interval of $0.18 \mathrm{sec}$. $(A)$ Small delta wave in lead $I$ and slurring of the $R$ upstroke in leads V4-V6 suggesting ventricular pre-excitation. (B) Signs of WPW with delta waves in leads $I, V_{5}$, and V6 and negative delta waves in leads $V_{I}$ and $V_{2}$. There is additional left axis deviation $\left(-45^{\circ}\right)$ on both tracings.

A. 28.12 .68

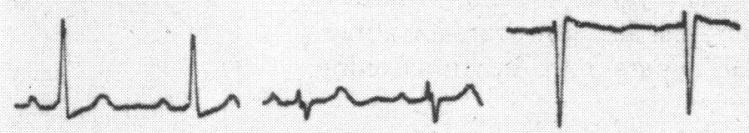

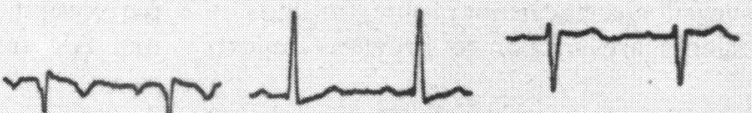

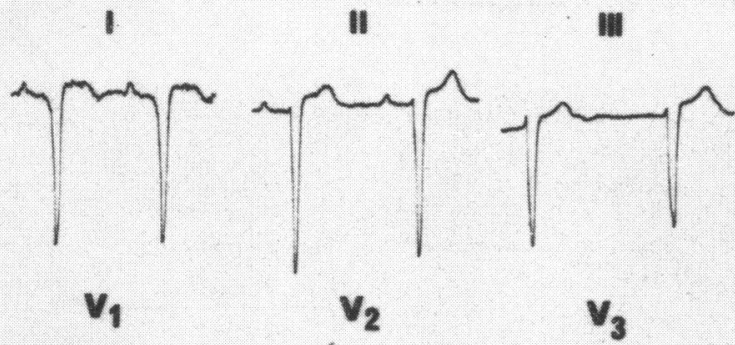<smiles>CCCCCC(C)(C)C</smiles>

aVL เที

\section{24.10 .69}

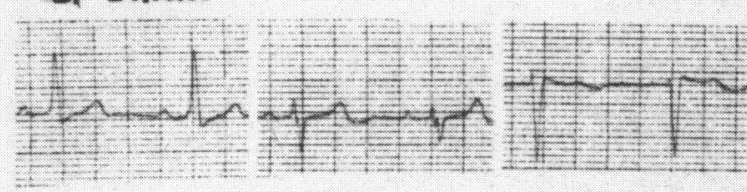

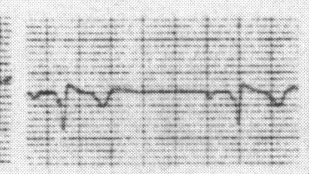

II

III

aVR

II<smiles>CCCCC(C)CC</smiles><smiles>CCCCCCC(C)C</smiles>

$v_{5}$

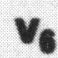

I

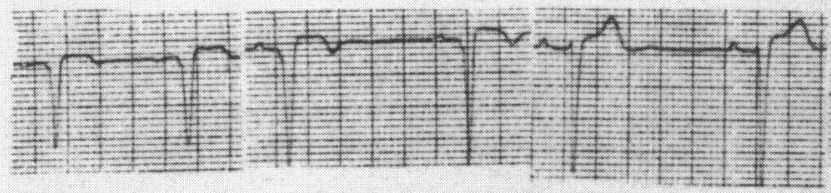

$v_{1}$

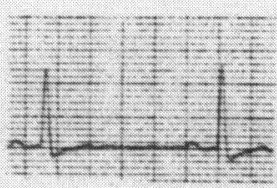

aVL

avF 
after the delta waves was prolonged to $0.12 \mathrm{sec}$, indicating additional left bundle-branch block. Delta waves were recorded on all tracings (Fig. 4).

\section{(C) Incomplete right bundle-branch block with abnormal $Q$ waves}

Case 4 In a conspicuously cyanosed woman, Ebstein's anomaly was diagnosed clinically at the age of 14 years. She had frequent attacks of paroxysmal tachycardia but no chest pain, and died suddenly at the age of 28 years. Necropsy showed the typical anomaly of the tricuspid valve. The left ventricular myocardium was normal without any signs of recent or previous ischaemia or infarction. The electrocardiogram in 1963 showed right atrial overload, PR interval of $0.24 \mathrm{sec}$, prominent $Q$ waves in lead III, and normal intraventricular conduction (Fig. 5A).

Nine months later an incomplete right bundlebranch block with rSr's' pattern in V2 was present, and broad $Q$ waves in leads III and aVF suggested an inferior wall infarction. The PR interval remained long and no positive delta waves could be seen (Fig. 5B).

During an attack of paroxysmal tachycardia aberrant intraventricular conduction of left bundle-branch block type was recorded (Fig. $5 \mathrm{C}$ ).

\section{Discussion}

The overall electrocardiographic findings in our patients are similar to previous reports
(Schiebler et al., 1959a; Genton and Blount, 1967; Lowe et al., 1968), showing right bundle-branch block, right atrial overload, and slightly prolonged PR interval as the dominant abnormality. The characteristic low voltage is, however, not invariably present. The incidence of ventricular pre-excitation in our patients, especially when the atypical cases are included, is somewhat higher than the 7-25 per cent mentioned in most series (Schiebler et al., I959b; Vacca et al., 1958; Lowe et al., 1968). The various morphologies of the WPW syndrome are the probable explanation of this difference.

The presentation of ventricular pre-excitation with delta waves and persistently normal PR interval in 2 patients with paroxysmal tachycardia is a prominent finding in this series. This is a rare but well-recognized abnormality (Pick and Katz, 1955; Chung, Walsh, and Massie, 1965), which may be explained by an anomalous conducting pathway between the lower AV node bundle of His and the upper posterior part of the ventricular septum (Fig. 6). In such cases the delta wave is the only sign of pre-excitation, since the supraventricular impulse is normally delayed in the AV node. During attacks of paroxysmal tachycardia, however, an abnormal AV nodal bypass may be functioning.

FIG. 4 Case 3. WPW syndrome with left bundle-branch block. PR interval of $0 \cdot 10$ sec, delta waves in leads $I, a V L$, and $V 5-V 7$. After the endpoint of the pre-excitation waves there is a further prolongation of the QRS complex to $0.12 \mathrm{sec}$.

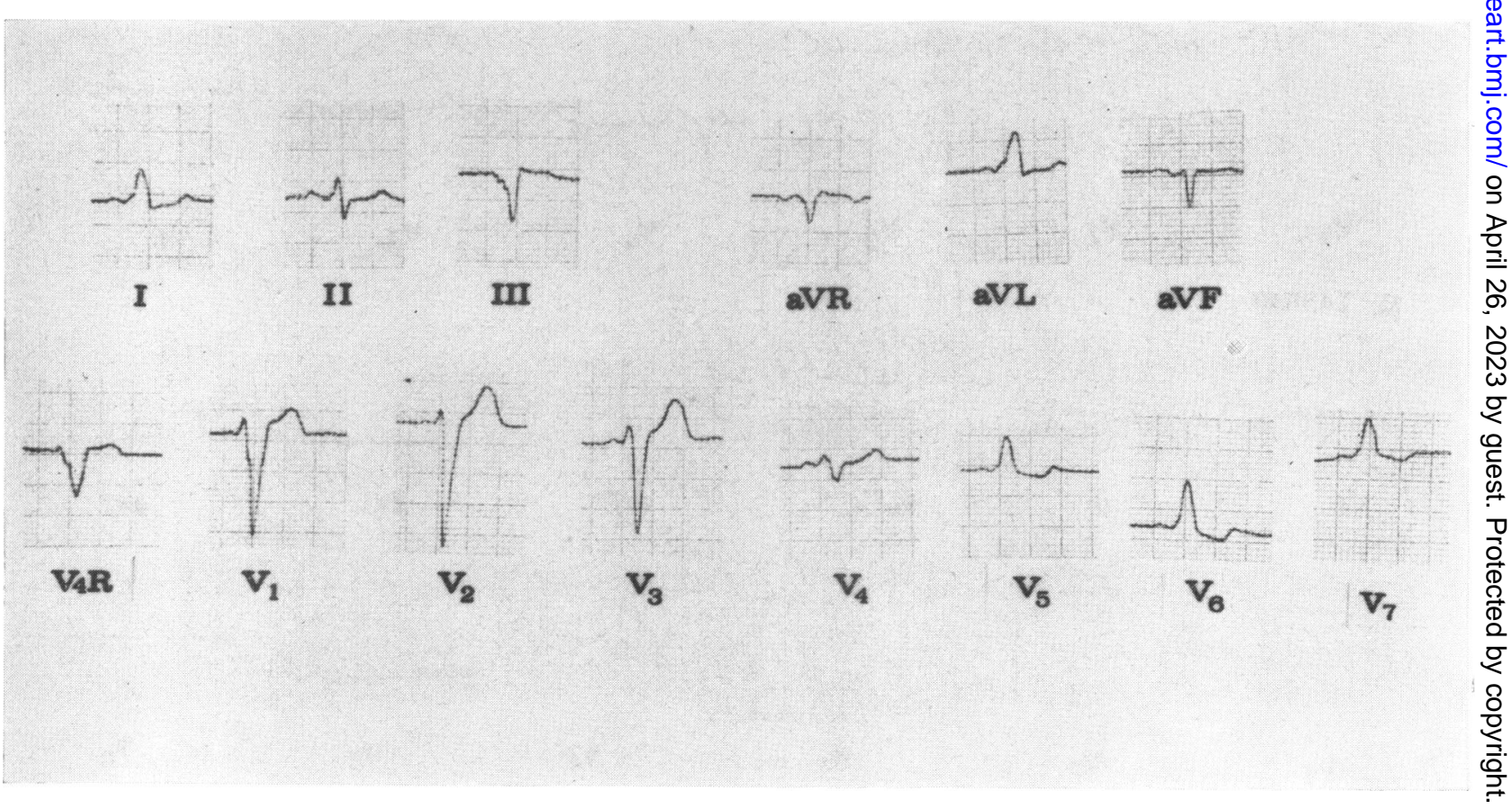


FIG. 5 Case 4. Conduction disturbances associated with abnormal $Q$ waves. $(A)$ Right atrial enlargement and first-degree $A V$ block $(P-R 0.24 \mathrm{sec})$. (B) Incomplete right bundle-branch block $\left(r S^{\prime} s^{\prime}\right.$ in $\left.V_{2}\right)$ with abnormal $Q$ waves of $0.04-0.06 \mathrm{sec}$ duration in lead III suggesting inferior - wall necrosis. (C) Aberrant intraventricular conduction of left bundle-branch block type during an attack of paroxysmal tachycardia.

\section{A. 5.10 .08}
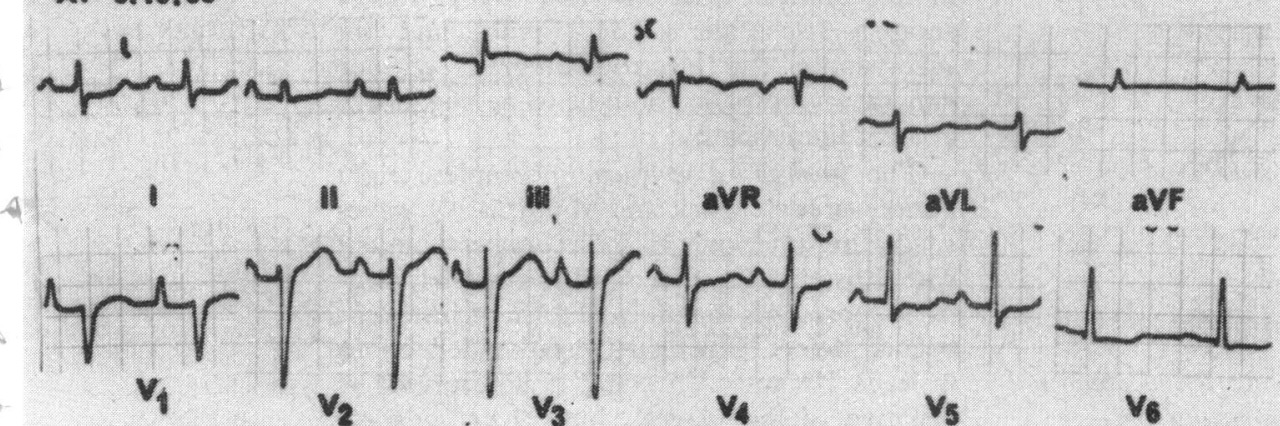

e. 19.5 .64
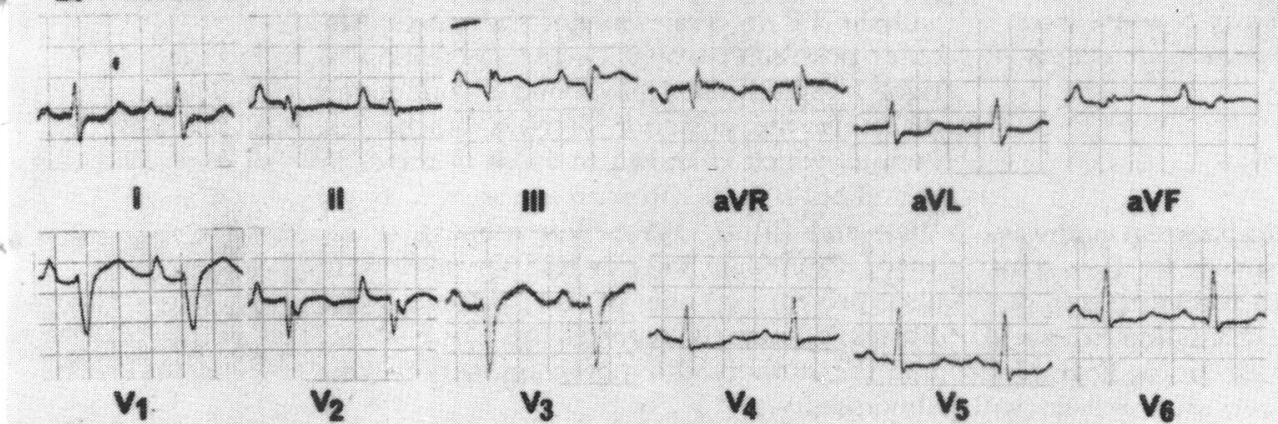

c.
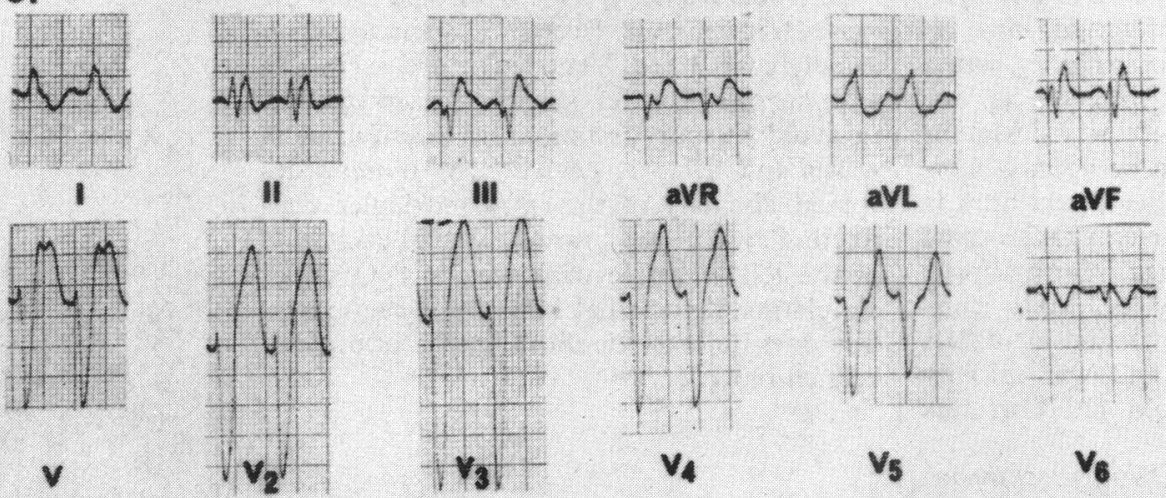


\section{ATRIUM}

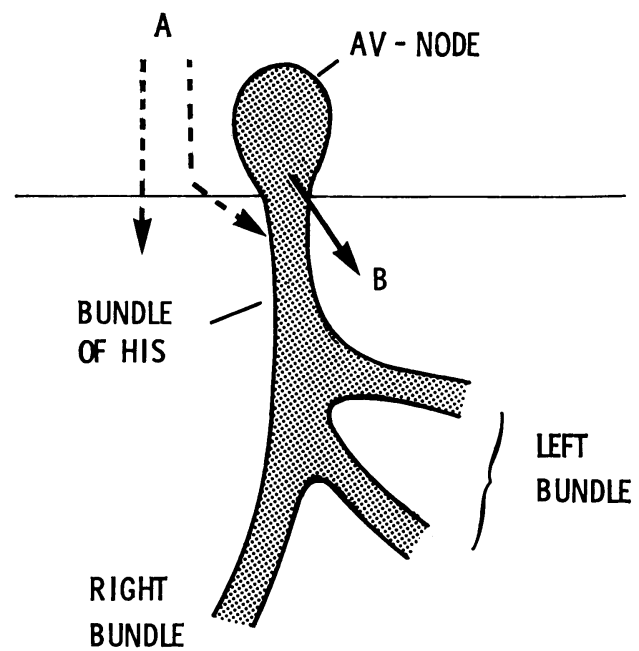

\section{VENTRICLE}

FIG. 6 Schematic representation of abnormal conduction pathways in ventricular preexcitation. $(A)$ Fibres bypassing the $A V$ node $(B)$. Anomalous pathway between lower part of the $A V$ node and ventricular septum (Mahaim fibres).

The existence of several abnormal pathways in the same heart was shown by Lev et al. (I966). It is important to recognize this rare form of ventricular pre-excitation to avoid misinterpretation of the electrocardiographic tracing. Negative delta waves are a well-known source of error even in the typical WPW syndrome; an inferior wall infarction may be diagnosed, especially in older patients, when the shortening of the PR interval is not present. The conspicuous left axis deviation observed in our patients can be equally misleading, since this abnormality in children is usually associated with atrioventricular canal defects or tricuspid atresia. Surprisingly enough, Ebstein's anomaly is rarely considered in the differential diagnosis of left axis deviation in children and was initially overlooked in the 3-year-old child in this series.

The combination of the Wolff-ParkinsonWhite syndrome and left bundle-branch block is highly unusual, but a few well-documented examples have been reported (Castellanos, Mayer, and Lemberg, 1962; Varriale, Alfenito, and Kennedy, 1966). In these cases the increased duration of the QRS complex is not only due to delta waves, but there is a true delay in left ventricular excitation. The left bundle-branch block pattern could be produced either by the slow progression of the pre-excitation impulse from the right to left ventricular myocardium bypassing the otherwise normal conducting system, or by an anatomical lesion in the left bundle. In the individual patient these mechanisms cannot be distinguished, unless an electrocardiogram shows persistent left bundle-branch block after the disappearance of pre-excitation, as in the case of Varriale et al. (1966). Left bundle-branch block is rare in Ebstein's anomaly (Schiebler et al., 1959b), and not surprisingly the electrocardiogram of our patient was initially thought to be suggestive of a cardiomyopathy.

The finding of atypical incomplete right bundle-branch block and abnormal $Q$ waves suggesting inferior wall infarction in a patient with Ebstein's anomaly and normal left ventricle represents the unusual form of intraventricular defect. The broad negative deflections in leads III and aVF could be interpreted as negative delta waves, but their positive counterpart was not seen in any other lead and the PR interval was not shortened. Another possibility would be the association of right bundle-branch block and a conduction defect in the posterior division of the left bundle, which is known to cause $Q$ waves in the inferior leads (Rosenbaum et al., 1969; Watt and Pruitt, 1969; Warembourg et al., 1970). Prominent inferior lead $Q$ waves were also present in one of the patients with Ebstein's anomaly reported by Lowe et al., but the authors did not comment on this abnormality.

In conclusion, WPW syndrome may be more frequent in Ebstein's anomaly than usually considered. Ventricular pre-excitation with normal PR interval should be recognized to avoid misinterpretation of negative delta waves and left axis deviation. A more widespread anomaly of the intraventricular conducting system can cause abnormal excitation of the left ventricle with abnormal $Q$ waves simulating myocardial infarction. Pre-excitation does not exclude the diagnosis of bundlebranch block.

We should like to thank Professor J. F. Goodwin for his advice and help. Richard Mazzei and David Privier (final year student from Detroit Medical School, U.S.A.) contributed to the analysis of patients with Ebstein's syndrome. We are grateful to the Department of Clinical Photography for the illustrations. 


\section{References}

Castellanos, A., Jr., Mayer, J. W., and Lemberg, L. (1962). The electrocardiogram and vectorcardiogram in Wolff-Parkinson-White syndrome associated with bundle branch block. American fournal of Cardiology, 10, 657.

Chung, K. Y., Walsh, T. J., and Massie, E. (1965).

- Wolff-Parkinson-White syndrome. American Heart Fournal, 69, 116.

Genton, E., and Blount, S. G., Jr. (1967). The spectrum of Ebstein's anomaly. American Heart fournal, 73, 395.

Lev, M., Leffler, W. B., Langendorf, J. R., and Pick,

A. (I966). Anatomic findings in a case of ventricular pre-excitation (WPW) terminating in complete atrioventricular block. Circulation, 34, 718.

Eowe, K. G., Emslie-Smith, D., Robertson, P. G. C., and Watson, H. (1968). Scalon, vector, and intracardiac electrocardiograms in Ebstein's anomaly. British Heart fournal, 30, 617.

Pick, A., and Katz, L. N. (1955). Disturbances of impulse formation and conduction in the pre-excita-

- tion (WPW) syndrome - their bearing on its mechanism. American fournal of Medicine, 19, 759.

Rosenbaum, M. B., Elison, M. V., Lazzari, J. O.,

- Nou, G. J., Levi, R. J., and Halpern, M. S. (1969). Intraventricular trifascicular blocks. The syndrome of right bundle branch block with intermittent left anterior and posterior hemiblock. American Heart fournal, 78, 306.
Schiebler, G. L., Adams, P., Jr., and Anderson, R. C. (1959a). The Wolff-Parkinson-White syndrome in infants and children. A review and report of 28 cases. Pediatrics, 24, 585.

Schiebler, G. L., Adams, P., Jr., Anderson, R. C., Amplatz, K., and Lester, R. G. (I959b). Clinical study of twenty-three cases of Ebstein's anomaly of the tricuspid valve. Circulation, 19, 165.

Vacca, J. B., Bussmann, D. W., and Mudd, J. G. (1958). Ebstein's anomaly. Complete review of 108 cases. American fournal of Cardiology, 2, 210.

Varriale, P. I., Alfenito, J., and Kennedy, R. J. (1966). The simultaneous occurrence of ventricular preexcitation, left bundle branch block, and delayed AV-conduction. American Heart fournal, 71, 803.

Warembourg, H., Pauchant, M., Théry, C., Lakieffre, J., Ducloux, G., and Gosselin, B. (1970). Bloc intraventriculaire postérieur au cours de l'insuffisance aortique. Archives des Maladies du Coeur et des Vaisseaux, 63, 408.

Watt, T. B., and Pruitt, R. D. (1969). Left posterior fascicular block in canine and primate hearts. Circulation, 40, 677 .

Requests for reprints to Dr. K. A. Hallidie-Smith, Department of Medicine (Clinical Cardiology), Royal Postgraduate Medical School, Hammersmith Hospital, Du Cane Road, London WI2. 